\title{
The Legacy of D. K. Lewis: Introduction to the Special Issue
}

\section{Marianna Antonutti Marfori² ${ }^{2}$ Pierluigi Graziani ${ }^{1}$}

Published online: 16 August 2020

(c) Springer Nature B.V. 2020

David Kellogg Lewis was without doubt the most influential philosopher of his generation. In 2005, Daniel Nolan wrote of him that "much of his influence has been as a 'philosopher's philosopher"'. The impact of Lewis's work on his contemporaries and on the following generations of philosophers has been both broad and deep. Using a Lewisian metaphor, one could say that his work is a coherent "mosaic" of ideas. This mosaic has been built step by step, tackling a number of philosophical issues and weaving a sophisticated and elegant dialogue with both the sciences and metaphysics.

In order to better understand the influence of the Lewisian mosaic, the APhEx group (www.aphex.it) and the Department of Philosophy of the University of Urbino organised in partnership an international conference entitled "Another World is Possible: Conference on David K. Lewis", 10 years after Lewis passed away. The conference took place in Urbino, Italy, from the 16th to the 18th of June, 2011. From the success of the conference, the idea was conceived of editing a collection specifically devoted to understanding Lewis's legacy in the different areas of philosophy that he influenced. Several years from the Urbino conference, we are happy to see this Special Issue finally appear. It includes some contributions that grew out of the conference, as well as many others that were written especially for this collection. We are particularly happy that a number of former doctoral students and collaborators of Lewis agreed to contribute to this project.

The publication of this Special Issue occurs in a period during which a number of important anniversaries concerning Lewis's life and work are being marked: 50 years since the publication of Lewis's first book "Convention: A Philosophical Study" in 1969 (based on his Ph.D. thesis at Harvard); the twentieth anniversary of the publication of the last volume of Lewis's collected works in 2000; and 20 years since Lewis's passing on October 14, 2001. This collection does not aim to reconstruct the

Pierluigi Graziani

pierluigi.graziani@uniurb.it

Marianna Antonutti Marfori

Marianna.AntonuttiMarfori@1rz.uni-muenchen.de

1 Department of Pure and Applied Sciences, University of Urbino, Urbino, Italy

2 Munich Center for Mathematical Philosophy, Ludwig-Maximilians-Universität München, Munich, Germany 
development of Lewis's thought, nor to provide an introduction to or overview of his work, for which excellent sources are already available. Rather, it aims to provide a window onto Lewis's enormous philosophical legacy by examining some of the most important ways in which Lewis's ideas continue to shape the development of contemporary philosophical research. Unfortunately, any collection that aims to undertake an endeavour like assessing Lewis's legacy can never fully succeed, partly because carrying out the task would involve more than a single volume can contain, and partly because the corpus of Lewis's legacy is constantly expanding. Due to the intrinsic limitations of such a project, this collection aims to illustrate only some of the aspects of this legacy.

This Special Issue collects 14 articles written by leading scholars, analysing some of the main themes in Lewis's philosophy: from the analysis of modality to modal realism, from the theory of counterparts to the criticisms of different kinds of ersatzism, from the analysis of mereological monism and Humean supervenience to that of unrestricted composition, from the counterfactual approach to causality to the counterfactual analysis of dispositions, from the concept of change to the notion of time, and concluding with an analysis of Lewis's epistemology.

The Special Issue opens with a series of papers concerning modality. The first paper is by John Divers (University of Leeds) and Jade Fletcher (University of Edinburgh), and is entitled "(Once Again) Lewis on the Analysis of Modality". The paper presents a new interpretation of Lewis's view of modality that distinguishes, and then integrates, the role of metaphysics and semantic theorising in the analysis of modal truth, thereby showing the limits of the received interpretations of Lewis. Subsequently, the paper presents a brief genealogy of Lewis's conception of modality and applies the proposed interpretation to the case of de re modality.

The second paper, "Genuine Modal Realism, the Humean Thesis and Advanced Modalizing” by Sònia Roca-Royes (University of Stirling), addresses the question of what interpretation is to be given, in Lewis's genuine modal realism, to advanced modalizing. Firstly, Roca-Royes considers the ramifications of Lewis's 1986 claim that the character of the totality of worlds is not a contingent matter, and argues that the claim is in tension with the Humean Thesis that genuine modal realism is supposed to endorse. She argues for a non-redundancy interpretation of advanced modalizing, whose merits are assessed with respect to their faithfulness to Lewis's thought and their advantages over available alternative interpretations.

The reflection on modality continues with a paper by Achille Varzi (Columbia University) entitled "Counterpart Theories for Everyone". The paper considers the relationship between Lewis's counterpart theory and Kripke-style semantics for modal logic, usually taken as two deeply divergent accounts of our modal talk, and examines how the two approaches differ in detail. Varzi then outlines a fully general framework that can accommodate both Lewis's counterpart-based account and Kripke's identity-based account as distinguished special cases, and evaluates the philosophical significance of this framework for our understanding of counterpart theory and modal logic in general.

The following two papers discuss Lewis's arguments against magical ersatzism, one of the aspects of Lewis's thought that is still underappreciated and not sufficiently well understood. In "It's a Kind of Magic: Lewis, Magic and Properties", Daniel 
Nolan (University of Notre Dame) analyses Lewis's notoriously difficult arguments against magical ersatzism as a way to illuminate not only what Lewis thought was wrong with a particular approach to possible worlds, but also with a good portion of the contemporary metaphysics of abstract objects. This analysis is then generalised to theories of properties and relations, revealing a new argument for concretism about possibilia.

Anthony Fisher (University of Manchester) continues the reflection on the significance of Lewis's criticism of magical or "non-descript" ersatzism in his paper "On Lewis Against Magic: A Study of Method in Metaphysics". After reconstructing Lewis's criticism in detail, Fisher shows how a closer look at Lewis's methodology reveals the broader objection he presented against magical ersatzism, as well as important aspects of Lewis's notion of ontological explanation and the justification of Lewis's philosophical methodology in general. ${ }^{1}$

"Mereological Monism and Humean Supervenience" by Andrea Borghini (University of Milan) and Giorgio Lando (University of L'Aquila), opens the discussion on mereology. The paper is devoted to the analysis of the relationship between Humean supervenience and mereological monism, two fundamental components of Lewis's thought, and argues that Humean supervenience is in tension with two philosophical theses entrenched with mereological monism, namely the hypothesis of gunk and the thesis of composition as identity.

"An Elegant Universe" by Claudio Calosi (University of Geneva) considers the controversial principle of unrestricted composition, whose acceptance was motivated by Lewis on the grounds of the alleged innocence of mereology, a thesis that has been widely criticised. In his paper, Calosi proposes a new way of arguing in support of unrestricted composition and shows that the endorsement of the proposed principle leads to a coherent, powerful, simple, and elegant metaphysical picture that includes extensionality of composition, functionality of location, and four-dimensionalism in metaphysics of persistence, theses that were endorsed by Lewis himself on independent grounds.

The eighth paper of the Special Issue is devoted to the analysis of the counterfactual approach to causation. In her paper entitled "Causation, Absences, and the Prince of Wales", Cei Maslen (Victoria University of Wellington) defends Lewis's counterfactual approach to causation by absences from important criticisms made by Carolina Sartorio by showing how Lewis's approach can deal both with problems of unwanted negative causes and unwanted positive causes, and with a problem of easy simultaneous causation that arises from relevant case studies.

Subsequently, Alan Hájek (Australian National University) discusses Lewis's counterfactual analysis of dispositions. In his paper entitled "Minkish Dispositions", Hájek argues that so-called finkish dispositions do not, as argued by many, refute the adequacy of the conditional analysis of disposition ascriptions. However, Hájek introduces the notion of a minkish disposition ("a disposition that something has, even though it might not display it in response to the relevant stimulus") and shows how this notion brings out an internal tension in Lewis's views: minkish dispositions not only undermine the

\footnotetext{
1 Note that this article belongs to the Special Issue on the Legacy of David Lewis but it was inadvertently included in issue 195(5):2335-2353 (2018), and can be accessed at https://doi.org/10.1007/s11229-015-0 679-3. It should be regarded as part of this selection of articles.
} 
adequacy of the counterfactual treatment of the canonical template that formalises a disposition ascription, but they also show how this analysis fails to capture the ordinary disposition ascription in the first place.

"Bringing Back Intrinsics to Enduring Things" by Andrea Bottani (University of Bergamo) investigates the argument known as "the argument from temporary intrinsics" which Lewis formulated, on behalf of perdurantism, as the strongest objection against endurantism. In this paper, Bottani provides a new analysis of the argument and focuses on three versions of eternalist endurantism, each of which brings back monadic intrinsics properties to enduring things while avoiding treating temporary intrinsics as relational, and argues that one of these alternatives is more plausible than the others. The conclusion is that while there are still reasons to be sceptical towards eternalist endurantism, the argument from temporary intrinsics does not conclusively undermine it, so that the best the perdurantist can achieve via this argument is stalemate.

The eleventh paper of the Special Issue, "Time Travel and Coincidence-Free Local Dynamical Theories" by Giuliano Torrengo (University of Milan), discusses the tension between the possibility of time travel and the "Autonomy Principle", according to which global constraints cannot override what is physically possible locally. Torrengo criticises Lockwood's solution to the "paradoxes" of time travel according to which the possibility of time travel is only compatible with the Autonomy Principle in the context of a 5D space-time-actuality manifold, and defends Lewis's "coincidence" solution by showing that shifting from 4D space-time to 5D space-time-actuality does not change the situation with respect to the Autonomy Principle.

Time travel is also the subject of “A Physical Interpretation of Lewis' Discrepancy between Personal and External Time in Time Travels" by Vincenzo Fano (University of Urbino) and Giovanni Macchia (University of Urbino). Fano and Macchia start from Lewis's famous 1976 article, in which he argues that time travel is metaphysically possible. By adapting Lewis's definition of time travel to the cosmological context, Fano and Macchia argue that, contrary to the popular view, journeys theorized on closed timelike curves of General Relativity can be assigned the status of proper time travels. Finally, they consider the consequences of their argument for realist views of time as a univocal entity of the world.

The last two papers of the Special Issue investigate aspects of Lewis's epistemology. “Simple Belief” by Jessica Collins (Columbia University) argues for the importance of having an epistemology of simple belief in addition to Bayesian epistemology, whose notion of belief admits of degree. Firstly, Collins draws on a distinction proposed by Lewis to identify the motivations for these two different accounts as stemming from two different pre-theoretical conceptions of unlikelihood, as improbability and as farfetchedness. Secondly, Collins proposes an account of when agents can rationally have a simple belief in a claim that does not reduce to properties of an agent's credence function and proposes a strategy for this account to deal with statistical inductive cases.

"Possibilities Regained: Neo-Lewisian Contextualism and Ordinary Life" by Nevia Dolcini (University of Macau) and Mario Piazza (Scuola Normale Superiore, Pisa), discusses another aspect of Lewis's epistemology, namely contextualism. Dolcini and Piazza analyse in detail what is involved in the rules proposed by Lewis in "Elusive Knowledge" concerning the truth conditions for the application of the predicate 'knows', which according to Lewis are context-sensitive. The authors identify some 
tensions in the evaluator's application of Lewisian rules, and some important ways in which the ordinary use of 'knows' differs from the use by the 'Lewisian' ordinary speaker. They then propose to add a new vector of value to Lewis's account, the socalled modal extroversion, which makes the satisfaction of 'knows better' depend on the discovery of actualised possibilities, together with their elimination, and allows them to advance a clear explanation of why 'knows' comes in degrees.

Finally, we would like to add some concluding remarks. Sadly, the publication of this Special Issue follows the recent passing of Steffi Lewis on November 7, 2019. The collection is dedicated to the memory of both Steffi and David Lewis.

We would like to thank the Editors in Chief of Synthese for supporting the project of this Special Issue. Special thanks go to Otávio Bueno for his invaluable assistance and advice during the preparation of the Special Issue, and for his enthusiasm for this project. We would like to thank the people without whom this project could not have seen the light of day: the authors, for accepting our invitation to contribute to this project, for submitting their outstanding work and advancing our understanding of Lewis's philosophical work and legacy, and for their patience in seeing the Special Issue completed, and the referees, for working alongside the authors and the editors in improving each individual paper-we regret being unable to thank them one by one. Lastly, we would like to thank the APhEx group and the colleagues from our respective universities for their continued support.

Work on this project was made possible by the generosity of our funding sources, whose support is gratefully acknowledged. Marianna Antonutti Marfori's work was supported by the German Research Foundation (Gefördert durch die Deutsche Forschungsgemeinschaft (DFG)—Projektnummer 390218268). Pierluigi Graziani's work was supported by the Italian Ministry of Education, University and Research through the PRIN 2017 project "The Manifest Image and the Scientific Image" prot. 2017ZNWW7F_004.

\section{Table of Contents}

1 John Divers and Jade Fletcher, "(Once Again) Lewis on the Analysis of Modality"

2 Sònia Roca-Royes, "Genuine Modal Realism, the Humean Thesis and Advanced Modalizing".

3 Achille Varzi, "Counterpart Theories for Everyone".

4 Daniel Nolan, "It's a Kind of Magic: Lewis, Magic and Properties".

5 Anthony Fisher, "On Lewis Against Magic: A Study of Method in Metaphysics".

6 Andrea Borghini and Giorgio Lando, "Mereological Monism and Humean Supervenience".

7 Claudio Calosi, "An Elegant Universe".

8 Cei Maslen, "Causation, Absences, and the Prince of Wales".

9 Alan Hájek, "Minkish Dispositions".

10 Andrea Bottani, "Bringing Back Intrinsics to Enduring Things".

11 Giuliano Torrengo, "Time Travel and Coincidence-Free Local Dynamical Theories". 
12 Vincenzo Fano and Giovanni Macchia, “A Physical Interpretation of Lewis' Discrepancy between Personal and External Time in Time Travels".

13 Jessica Collins, "Simple Belief".

14 Nevia Dolcini and Mario Piazza, "Possibilities Regained: Neo-Lewisian Contextualism and Ordinary Life".

Publisher's Note Springer Nature remains neutral with regard to jurisdictional claims in published maps and institutional affiliations. 